\title{
The disease burden attributable to 18 occupational risks in China: an analysis for the global burden of disease study 2017
}

Jie Li', Peng Yin ${ }^{1}$, Haidong Wang ${ }^{2}$, Xinying Zeng ${ }^{3}$, Xiao Zhang ${ }^{1}$, Lijun Wang ${ }^{1}$, Jiangmei Liư, Yunning Liu', Jinling You', Zhenping Zhao', Shicheng $\mathrm{Yu}^{3}$ and Maigeng Zhou ${ }^{1 *}$ (D)

\begin{abstract}
Background: China has more than 18\% of the global population and over 770 million workers. However, the burden of disease attributable to occupational risks is unavailable in China. We aimed to estimate the burden of disease attributable to occupational exposures at provincial levels from 1990 to 2017.

Methods: We estimated the summary exposure values (SEVs), deaths and disability-adjusted life years (DALYs) attributable to occupational risk factors in China from 1990 to 2017, based on Global Burden of Disease Study (GBD) 2017. There were 18 occupational risks, 22 related causes, and 35 risk-outcome pairs included in this study. Meanwhile, we compared age-standardized death rates attributable to occupational risk factors in provinces of China by socio-demographic index (SDI).

Results: The SEVs of most occupational risks increased from 1990 to 2017. There were 323,833 (95\% UI 283,780 $369,061)$ deaths and $14,060,210(12,022,974-16,125,763)$ DALYs attributable to total occupational risks in China, which were 27.9 and $22.1 \%$ of corresponding global levels, respectively. For attributable deaths, major risks came from occupational particulate matter, gases, and fumes (PGFs), and for the attributable DALYs, from occupational injuries. The attributable burden was higher in males than in females. Compared with high SDI provinces, low SDI provinces, especially Western China, had higher death rates attributable to total occupational risks, occupational PGFs, and occupational injuries.

Conclusion: Occupational risks contribute to a huge disease burden in China. The attributable burden is higher in males, and in less developed provinces of Western China, reflecting differences in risk exposure, socioeconomic conditions, and type of jobs. Our study highlights the need for further research and focused policy interventions on the health of workers especially for less developed provinces in China to reduce occupational health losses effectively.
\end{abstract}

Keywords: Death, Attributable burden, Occupational risk, Risk exposure

\section{Introduction}

China is the most populous country in the world with a population of 1.37 billion [1]. Over the past few decades, China has emerged as a global leader in manufacturing with growing competitiveness and increasing impact on the global economy. However, rapid economic growth

\footnotetext{
* Correspondence: zhoumaigeng@ncncd.chinacdc.cn

${ }^{1}$ National Center for Chronic and Noncommunicable Disease Control and Prevention, Chinese Center for Disease Control and Prevention, 27 Nanwei Road, Xicheng District, Beijing 100050, China

Full list of author information is available at the end of the article
}

also brings to the workplace a variety of risks that threaten the health of workers. There are more than 770 million workers in China, and more than 200 million workers are exposed to occupational hazards $[1,2]$. It has become a priority for China to meet the challenges in the monitoring of the health of workers and in the improvement of occupational health services.

Occupational risks, as part of environmental hazards, contribute to the development of many diseases and injuries [3-9]. By evaluating burden attributable to occupational risks, accurate and comprehensive data can be

(c) The Author(s). 2020 Open Access This article is distributed under the terms of the Creative Commons Attribution 4.0 International License (http://creativecommons.org/licenses/by/4.0/), which permits unrestricted use, distribution, and 
offered to policymakers to effectively prevent related health losses. Although attempts have been made to estimate the burden of air pollution at the national level $[10,11]$, only a few studies estimated the burden of occupational carcinogens and injuries and they were limited to several provinces of China [12-14]. Additionally, occupational exposure exhibits spatial and temporal heterogeneity and is closely related to socioeconomic levels in different regions. Therefore, a comprehensive study on the spatiotemporal trend of the burden of disease attributable to occupational risks is urgently needed in China.

In this paper, we evaluated the disease burden levels attributable to 18 occupational risks and their geographical heterogeneity by socio-demographic index (SDI) in China from 1990 to 2017, as part of the Global Burden of Disease Study 2017 (GBD 2017). We aimed to find out the key problems in occupational health so as to provide useful information for occupational protection strategies and interventions in China.

\section{Methods}

\section{Overview}

The comparative risk assessment (CRA) approach was developed to estimate levels and trends of sex-specific, risk-specific, and cause-specific mortality and disease burden of behavioral, environmental, occupational, and metabolic risks from 1990 to 2017 for 195 countries and territories in GBD 2017 [15]. The detailed framework and data analysis methods have been provided previously [16-18]. In the CRA framework, the attributable burden was calculated as the reduction in the current disease burden if the past population exposure shifted to the counterfactual level of risk exposure. By using a consistent approach, CRA allows rankings and comparisons among deaths and DALYs attributable to various risk factors, providing further data guidance for policymakers. SDI as a combined indicator was estimated based on fertility among women, years of education and income per person. The SDI of China in 2017 was estimated in our previous article [19]. Here we focused on accessible data of occupational risks from GBD 2017 to estimate the disease burden attributable to occupational exposure in China.

\section{Risk factors and related causes}

Risk-outcome pairs satisfying the World Cancer Research Fund (WCRF) grades of convincing or probable evidence with biologically plausible associations were included in GBD 2017 [15]. There are 18 occupational risks, 22 related causes and 35 risk-outcome pairs included in this study. The occupational risk factors hierarchy and related causes were shown in Table 1 . There are six risk categories including carcinogens, asthmagens, PGFs, noise, injuries, and
Table 1 Occupational risk factors hierarchy and related causes included in GBD 2017

\begin{tabular}{|c|c|c|}
\hline \multicolumn{2}{|c|}{ Occupational risk factors } & \multirow{2}{*}{$\begin{array}{l}\text { Related causes } \\
\text { Asthma }\end{array}$} \\
\hline 3 & Asthmagens & \\
\hline 3 & Carcinogens & \\
\hline 4 & Arsenic & $\begin{array}{l}\text { Tracheal, bronchus, } \\
\text { and lung cancer }\end{array}$ \\
\hline \multirow[t]{5}{*}{4} & Asbestos & Larynx cancer \\
\hline & & Mesothelioma \\
\hline & & Ovarian cancer \\
\hline & & Pneumoconiosis \\
\hline & & $\begin{array}{l}\text { Tracheal, bronchus, } \\
\text { and lung cancer }\end{array}$ \\
\hline 4 & Benzene & Leukemia \\
\hline 4 & Beryllium & $\begin{array}{l}\text { Tracheal, bronchus, } \\
\text { and lung cancer }\end{array}$ \\
\hline 4 & Cadmium & $\begin{array}{l}\text { Tracheal, bronchus, } \\
\text { and lung cancer }\end{array}$ \\
\hline 4 & Chromium & $\begin{array}{l}\text { Tracheal, bronchus, } \\
\text { and lung cancer }\end{array}$ \\
\hline 4 & $\begin{array}{l}\text { Diesel engine } \\
\text { exhaust }\end{array}$ & $\begin{array}{l}\text { Tracheal, bronchus, } \\
\text { and lung cancer }\end{array}$ \\
\hline \multirow[t]{2}{*}{4} & Formaldehyde & Leukemia \\
\hline & & $\begin{array}{l}\text { Nasopharynx } \\
\text { cancer }\end{array}$ \\
\hline 4 & Nickel & $\begin{array}{l}\text { Tracheal, bronchus, } \\
\text { and lung cancer }\end{array}$ \\
\hline 4 & $\begin{array}{l}\text { Polycyclic aromatic } \\
\text { hydrocarbons }\end{array}$ & $\begin{array}{l}\text { Tracheal, bronchus, } \\
\text { and lung cancer }\end{array}$ \\
\hline \multirow[t]{2}{*}{4} & Silica & Pneumoconiosis \\
\hline & & $\begin{array}{l}\text { Tracheal, bronchus, } \\
\text { and lung cancer }\end{array}$ \\
\hline 4 & Sulfuric acid & Larynx cancer \\
\hline 4 & Trichloroethylene & Kidney cancer \\
\hline 3 & Ergonomic factors & Low back pain \\
\hline \multirow[t]{10}{*}{3} & Injuries & Road injuries \\
\hline & & Falls \\
\hline & & Drowning \\
\hline & & $\begin{array}{l}\text { Exposure to } \\
\text { mechanical forces }\end{array}$ \\
\hline & & Poisonings \\
\hline & & $\begin{array}{l}\text { Other transport } \\
\text { injuries }\end{array}$ \\
\hline & & $\begin{array}{l}\text { Other unintentional } \\
\text { injuries }\end{array}$ \\
\hline & & $\begin{array}{l}\text { Fire, heat, and hot } \\
\text { substances }\end{array}$ \\
\hline & & Animal contact \\
\hline & & Foreign body \\
\hline 3 & Noise & $\begin{array}{l}\text { Age-related and } \\
\text { other hearing loss }\end{array}$ \\
\hline \multirow[t]{2}{*}{3} & Particulate matter, & COPD \\
\hline & & Pneumoconiosis \\
\hline
\end{tabular}

ergonomic factors for occupational risks. The occupational carcinogens include 13 agents classified as Group 1 carcinogens by the International Agency for Research on Cancer (IARC). The exposure definitions, International Classification of Diseases (ICD) codes of related cases, and 
epidemiological evidence supporting risk-outcome pairs are listed in Tables S1-S3.

\section{Estimation of exposure}

Data for occupational risk factors were collected from all accessible resources. The data included raw data on Chinese economic activity proportions, occupation proportions, employment to population ratio estimates, and fatal injury rates from the International Labour Organization, survey data including China National Population Census, China Intercensal Population Sample Survey of One-Percent, China International Social Survey Programme [15]. The Spatio-temporal Gaussian process regression (ST-GPR) approach was used to integrate multiple data inputs and generate year-specific, and location-specific estimates. For each occupational risk, the theoretical minimum risk exposure level (TMREL) was assumed to no given risk exposure or the lowest levels of risk exposure without established riskoutcome (Table S1). Education, geological information and the socio-demographic level were included in models as covariates. The estimates differed for (1) occupational carcinogens, occupational noise, and occupational particulates, (2) occupational ergonomic factors and occupational asthmagens, and (3) occupational injuries using the following equations:

$$
\begin{aligned}
& \mathrm{E}_{r, p, l, y, s, a}=\sum_{e}\left(\mathrm{P}_{e, p, y} * \mathrm{EAP}_{p, y, s, a} * \text { Exposure rate }_{r, l, e}\right) \\
& \mathrm{E}_{r, p, y, s, a}=\sum_{e}\left(P_{o c c, p, y} * E A P_{p, y, s, a}\right)
\end{aligned}
$$

$$
\text { Occupational fatal injuries }{ }_{p, y, s, a}
$$

$=\sum_{e}\left(\right.$ Injury rate $_{e, p, y, s} *$ Population $\left._{p, y, s, a} * E A P_{p, y, s, a} * P_{e, p, y}\right)$

Where $E_{r, p, l, y, s, a}$ is the prevalence of exposure for risk factor $\mathrm{r}$ in province $\mathrm{p}$ at level $\mathrm{l}$ in year $\mathrm{y}$, sex $\mathrm{s}$, and age group a. $\mathrm{P}_{\mathrm{e}, \mathrm{p}, \mathrm{y}}$ is the proportion of economically active population in province $\mathrm{p}$, economic activity e, and year $\mathrm{y} . \mathrm{EAP}_{\mathrm{p}, \mathrm{y}, \mathrm{s}, \mathrm{a}}$ is economically active population in province $\mathrm{p}$, year $\mathrm{y}$, sex $\mathrm{s}$ and age group a. Exposure rate r,l,e $_{\mathrm{e}}$ is the rate of exposure to risk factor $r$ at level 1 in economic activity e. $E_{r, p, y, s, a}$ is the prevalence of exposure for risk $r$ in province $p$, year $y$, sex $s$, and age group a. $\mathrm{P}_{\mathrm{occ}, \mathrm{p}, \mathrm{y}}$ is the proportion of economically active population in occupation occ in province $\mathrm{p}$, and year y. Occupational fatal injuries p $, \mathrm{y}, \mathrm{s}, \mathrm{a}_{\mathrm{a}}$ is the occupational fatal injuries counts in province p, year y, sex s and age group a. Injury rate e,p,y,s $_{\text {is }}$ ine injury rate of economic activity e in province $\mathrm{p}$, year $\mathrm{y}$ and sex s. Population $\mathrm{p}_{\mathrm{p}, \mathrm{y}, \mathrm{s}, \mathrm{a}}$ is the population in year $y$, province $\mathrm{p}$, sex $\mathrm{s}$ and age group a. All occupational risk exposures were estimated for ages 15 and older. The estimates were further divided by the sum of all the estimates to be rescaled to sum as 1 across different categories.

\section{Relative risks and the population attributable fraction}

Information from the cohort, pooled cohort, and casecontrol studies was obtained to determine the relative risk for each risk-outcome pair by systematic reviews in GBD 2017 [15]. The risk factors were categorized based on the measurement of exposure: dichotomous, polytomous, and continuous. The relative risks for each exposure category were listed in Tables S4 and S5.

The population attributable fraction (PAF) is the proportion of outcomes or causes in the population that are attributable to the associated risk factor [20]. It is estimated independently by relative risks and calculated as the proportion of the decreased outcome among a given population if the past exposure levels of risk were reduced to the counterfactual level of the TMREL in a given year.

The equation for calculating PAFs of occupational risks with the exception of injuries:

$$
P A F_{r, c, p, y, s, a}=\frac{\sum_{x=l}^{u} R R_{r, c, s, a}(x) * P_{r, p, y, s, a}(x)-R R_{r, c, p, s, a}\left(T M R E L_{r, s, a}\right)}{\sum_{x=l}^{u} R R_{r, c, s, a}(x) * P_{r, p, y, s, a}(x)}
$$

Where $\operatorname{PAF}_{\mathrm{r}, \mathrm{c}, \mathrm{p}, \mathrm{y}, \mathrm{s}, \mathrm{a}}$ is the population attributable fraction for cause $\mathrm{c}$ due to risk factor $\mathrm{r}$ in province $\mathrm{p}$, year $\mathrm{y}$, sex $\mathrm{s}$ and age group a. $R R_{r, c, s, a}$ is the relative risk as a function of exposure level $\mathrm{x}$ (ranged from lowest exposure level (l) to highest exposure level (u)) for risk $r$, cause c, sex s, and age group a. $P_{r, p, y, s, a}(x)$ is the distribution of exposure for risk $r$, in province $p$, year $y$, sex $s$, and age group a. TMREL $L_{r, s, a}$ is the theoretical minimum risk exposure level for risk factor $r$, sex s, and age group a.

The equation for calculating PAFs of occupational injuries:

$$
P A F_{p, y, s, a}=\frac{{\text { Occupational fatal } \text { injuries }_{p, y, s, a}-\text { TMREL }}_{\text {Fatal injuries }}^{p, y, s, a}}{\text { in }}
$$

Where $\operatorname{PAF}_{\mathrm{p}, \mathrm{y}, \mathrm{a}, \mathrm{s}}$ is the population attributable fraction in province $\mathrm{p}$, year $\mathrm{y}$, sex $\mathrm{s}$ and age group a. Occupational fatal injuries $s_{p, y, s, a}$ is the occupational fatal injuries counts in province $\mathrm{p}$, year $\mathrm{y}$, sex $\mathrm{s}$ and age group a. Fatal injuries $_{\mathrm{p}, \mathrm{y}, \mathrm{s}, \mathrm{a}}$ is the total fatal injuries counts in province $\mathrm{p}$, year $\mathrm{y}$, sex s and age group a, which were obtained from causes of death in GBD 2017 [15]. And the PAFs of multiple risks are aggregated by a mediation adjustment to calculate the excess attenuated risk. The PAFs for different causes were shown in Table S6. 


\section{Estimation of attributable burden}

For the given exposure risk-outcome pair, the attributable deaths were estimated as total deaths for the outcome multiplied by the PAF for the risk-outcome pair [15]. The other three metrics of burden including years of life lost (YLLs), years lived with disability (YLDs), and DALYs (the sum of YLLs and YLDs) were also assessed in a similar way. The attributable burden was estimated by location, age, sex, and year. The standard population from WHO was used to calculate age-standardized deaths and DALYs per capita for each country.

\section{Summary exposure values}

Summary exposure values (SEV) is an exposure metric of the risk-weighted prevalence of each risk [15]. SEV standardizes the prevalence by relative risks of related causes to offer a concise comparable summary of risk exposure for different locations and years. The range of SEV is from 0 to $100 \%$, where $0 \%$ indicates no given risk exposure in a population, and $100 \%$ means the total population is exposed to the maximum possible level for a given risk.

\section{Results}

There were SEVs for 17 occupational risks with the exception of occupational injuries in GBD 2017 (Table 2). The leading exposure category for SEVs was ergonomic factors, followed by asthmagens, noise, and PGFs. All-age SEVs of 15 in 17 occupational risks increased from 1990 to 2017 in China. Age-standardized SEVs for three risks increased by more than 20\% from 1990 to 2017: occupational exposure to benzene, trichloroethylene, and chromium. Conversely, SEVs for occupational ergonomic factors and asthmagens decreased by more than $20 \%$.

As shown in Table 3, there were 323,833 (95\% UI 283780-369,061) deaths attributable to total occupational risks in 2017, China, which accounted for $27.9 \%$ of global attributable deaths. The deaths attributable to PGFs, carcinogens, injuries, and asthmagens accounted for $57.8,21.1,20.8,0.2 \%$ of deaths attributable to total occupational risks in 2017, respectively. From 1990 to 2017, age-standardized death rate attributable to injuries, PGFs and asthmagens declined by more than $60 \%$, but the rate attributable to carcinogens increased by $16.8 \%$.

As shown in Table 4, there were 14,060,210 (12,022, 974 - 16,125,763) DALYs attributable to total occupational risks in 2017, China, which accounted for $22.1 \%$

Table 2 All-age and age-standardized summary exposure values for occupational risk factors, 1990, and 2017 in China, with mean percentage change for 1990-2017

\begin{tabular}{|c|c|c|c|c|c|c|}
\hline \multirow[t]{2}{*}{ Occupational risks } & \multicolumn{3}{|l|}{ All-age SEVs } & \multicolumn{3}{|c|}{ Age-standardized SEVs } \\
\hline & 1990 & 2017 & $\begin{array}{l}\text { Percentage change } \\
(\%)\end{array}$ & 1990 & 2017 & $\begin{array}{l}\text { Percentage change } \\
(\%)\end{array}$ \\
\hline Asthmagens & $14.18(11.46-17.52)$ & $13.35(11.15-15.77)$ & $-5.84(-19.48-10.57)$ & $14.15(11.43-17.33)$ & $10.77(9.04-12.74)$ & $-23.89(-34.57--12.36)$ \\
\hline Ergonomic factors & $21.04(19.22-22.91)$ & 16.62 (14.42-19.04) & $-20.99(-32.18--9.47)$ & 20.97 (19.21-22.75) & $13.40(11.66-15.30)$ & $-36.10(-44.96--26.78)$ \\
\hline \multicolumn{7}{|l|}{ Carcinogens } \\
\hline Arsenic & $0.32(0.13-0.55)$ & $0.55(0.22-0.92)$ & $67.96(54.02-83.30)$ & $0.35(0.14-0.59)$ & $0.40(0.16-0.67)$ & $12.88(3.53-23.23)$ \\
\hline Asbestos & $0.30(0.22-0.43)$ & $0.70(0.62-0.76)$ & $131.64(52.45-229.15)$ & $0.43(0.32-0.59)$ & $0.51(0.45-0.56)$ & $20.10(-19.30-64.12)$ \\
\hline Benzene & $0.50(0.31-0.88)$ & $0.67(0.40-1.19)$ & $34.52(27.40-43.40)$ & $0.46(0.28-0.82)$ & $0.57(0.34-1.02)$ & $22.65(16.16-30.74)$ \\
\hline Beryllium & $0.09(0.08-0.09)$ & $0.13(0.13-0.13)$ & $51.82(46.12-57.95)$ & $0.09(0.09-0.09)$ & $0.09(0.09-0.10)$ & $1.80(-1.99-5.95)$ \\
\hline Cadmium & $0.17(0.16-0.18)$ & $0.28(0.26-0.31)$ & $67.92(55.20-81.64)$ & $0.18(0.18-0.19)$ & $0.21(0.19-0.22)$ & $12.83(4.22-22.04)$ \\
\hline Chromium & $0.34(0.32-0.35)$ & $0.60(0.55-0.65)$ & 78.75 (63.86-94.15) & $0.36(0.35-0.38)$ & $0.43(0.40-0.47)$ & $20.18(10.22-30.54)$ \\
\hline DEE & $1.41(1.36-1.46)$ & $2.41(2.28-2.55)$ & $71.01(60.03-82.29)$ & $1.52(1.47-1.58)$ & $1.75(1.65-1.85)$ & $14.92(7.51-22.45)$ \\
\hline Formaldehyde & $0.78(0.74-0.81)$ & $1.02(0.92-1.11)$ & $30.80(18.62-44.18)$ & $0.73(0.69-0.76)$ & $0.87(0.79-0.94)$ & $19.28(8.09-31.25)$ \\
\hline Nickel & $0.36(0.12-0.94)$ & $0.54(0.18-1.42)$ & $51.27(40.12-64.95)$ & $0.39(0.13-1.01)$ & $0.39(0.13-1.03)$ & $1.63(-5.88-10.79)$ \\
\hline PAHs & $0.68(0.65-0.70)$ & $1.19(1.10-1.28)$ & 76.01 (61.72-90.71) & $0.73(0.70-0.76)$ & $0.86(0.80-0.93)$ & $18.33(8.70-28.24)$ \\
\hline Silica & $3.20(1.68-6.99)$ & $4.49(2.30-9.68)$ & $40.16(29.8-51.94)$ & $3.45(1.81-7.54)$ & $3.25(1.67-7.01)$ & $-5.75(-12.79-2.12)$ \\
\hline Sulfuric acid & $0.76(0.55-1.31)$ & $1.20(0.86-2.12)$ & $58.34(47.62-69.35)$ & $0.82(0.59-1.41)$ & $0.87(0.62-1.53)$ & $6.32(-0.87-13.70)$ \\
\hline Trichloroethylene & $0.19(0.18-0.19)$ & $0.34(0.32-0.36)$ & 80.12 (69.16-93.03) & $0.20(0.20-0.21)$ & $0.24(0.23-0.26)$ & $21.05(13.63-29.70)$ \\
\hline Noise & $8.11(7.67-8.57)$ & $12.30(11.75-12.95)$ & $51.73(46.79-57.63)$ & $9.23(8.73-9.83)$ & $9.24(8.82-9.76)$ & $0.12(-2.85-3.28)$ \\
\hline PGFs & $8.30(6.88-10.32)$ & $12.12(10.08-14.70)$ & $46.09(35.82-55.38)$ & $9.28(7.72-11.42)$ & $9.18(7.7-11.22)$ & $-1.10(-4.69-2.89)$ \\
\hline
\end{tabular}

SEV Summary exposure value, UI Uncertain interval, PGFs Particulate matter, gases, and fumes, DEE Diesel engine exhaust, PAHs Polycyclic aromatic hydrocarbons 
Table 3 Deaths and age-standardized death rate for occupational risk factors, 1990, and 2017 in China, with mean percentage change for 1990-2017

\begin{tabular}{|c|c|c|c|c|c|c|}
\hline \multirow[t]{2}{*}{ Occupational risks } & \multicolumn{3}{|l|}{ Deaths } & \multicolumn{3}{|c|}{ Age-standardized death rate (per 100,000) } \\
\hline & 1990 & 2017 & $\begin{array}{l}\text { Percentage } \\
\text { change (\%) }\end{array}$ & 1990 & 2017 & $\begin{array}{l}\text { Percentage } \\
\text { change (\%) }\end{array}$ \\
\hline Asthmagens & $3039(1765-4108)$ & $792(631-992)$ & $-73.9(-82.0--49.8)$ & $0.30(0.17-0.42)$ & $0.04(0.03-0.05)$ & $-87.1(-91.3--74.6)$ \\
\hline Carcinogens & $26,546(20385-33,149)$ & $68,396(53282-85,467)$ & $157.7(121.5-200.4)$ & $3.00(2.33-3.70)$ & $3.50(2.75-4.35)$ & $16.8(-0.1-36.8)$ \\
\hline Arsenic & $1324(514-2188)$ & $3725(1402-6118)$ & $181.4(149.0-218.6)$ & $0.14(0.05-0.23)$ & $0.18(0.07-0.29)$ & $29.9(15.1-47.1)$ \\
\hline Asbestos & $5796(3962-8718)$ & $24,264(16700-32,287)$ & $318.7(185.4-451.4)$ & $0.78(0.54-1.17)$ & $1.36(0.94-1.81)$ & $73.6(20.0-126.9)$ \\
\hline Benzene & $380(107-643)$ & $372(108-625)$ & $-2.22(-15.9-23.3)$ & $0.03(0.01-0.05)$ & $0.02(0.01-0.03)$ & $-32.0(-42.0-15.0)$ \\
\hline Beryllium & $57(47-68)$ & $149(122-179)$ & $161.4(132.5-188.4)$ & $0.01(0.00-0.01)$ & $0.01(0.01-0.01)$ & $20.7(8.2-33.0)$ \\
\hline Cadmium & $129(109-150)$ & $364(302-434)$ & $182.1(148.9-219.8)$ & $0.01(0.01-0.02)$ & $0.02(0.01-0.02)$ & $30.2(15.2-47.3)$ \\
\hline Chromium & $244(216-277)$ & $727(625-830)$ & $197.5(163.3-235.1)$ & $0.03(0.02-0.03)$ & $0.03(0.03-0.04)$ & $37.3(21.8-54.1)$ \\
\hline DEE & $2762(2418-3125)$ & $8083(6960-9319)$ & $192.7(155.7-224.9)$ & $0.28(0.25-0.32)$ & $0.38(0.33-0.44)$ & $35.1(18.6-49.7)$ \\
\hline Formaldehyde & $408(317-505)$ & 391 (306-494) & $-4.2(-20.7-14.5)$ & $0.03(0.03-0.04)$ & $0.02(0.02-0.03)$ & $-41.1(-49.9--31.6)$ \\
\hline Nickel & $1488(292-3334)$ & $3803(762-8450)$ & $155.5(126.1-188.6)$ & $0.15(0.03-0.34)$ & $0.18(0.04-0.40)$ & $18.0(4.4-33.1)$ \\
\hline PAHs & $852(722-980)$ & $2500(2092-2937)$ & $193.5(157.4-231.2)$ & $0.09(0.07-0.10)$ & $0.12(0.10-0.14)$ & $35.5(19.4-52.8)$ \\
\hline Silica & $13,260(8742-18,469)$ & $25,073(14869-35,605)$ & $89.1(51.3-123.9)$ & $1.46(0.97-2.02)$ & $1.23(0.74-1.73)$ & $-15.7(-34.0-1.0)$ \\
\hline Sulfuric acid & 419 (173-778) & $719(301-1348)$ & $71.8(56.5-91.2)$ & $0.04(0.02-0.08)$ & $0.03(0.01-0.06)$ & $-21.3(-28.4--12.4)$ \\
\hline Trichloroethylene & $4(1-7)$ & $14(3-26)$ & $285.4(172.9-364.0)$ & $0.00(0.00-0.00)$ & $0.00(0.00-0.00)$ & $81.1(27.8-118.2)$ \\
\hline Injuries & $142,834(120521-167,777)$ & $67,461(57132-79,340)$ & $-52.8(-61.9--41.0)$ & $11.95(10.10-14.02)$ & $3.84(3.25-4.52)$ & $-67.9(-74.0--59.8)$ \\
\hline PGFs & $240,075(197593-281,136)$ & $187,184(148439-228,139)$ & $-22.0(-31.5--5.1)$ & $37.20(29.5-44.73)$ & $11.36(8.82-14.03)$ & $-69.5(-72.5--63.2)$ \\
\hline $\begin{array}{l}\text { All occupational } \\
\text { risks }\end{array}$ & $412,493(362216-461,292)$ & $323,833(283780-369,061)$ & $-21.5(-29.5--10.8)$ & $52.45(44.51-60.48)$ & $18.74(16.17-21.56)$ & $-64.3(-67.5--59.3)$ \\
\hline
\end{tabular}

Uls Uncertainty intervals, PGFs Particulate matter, gases, and fumes, DEE Diesel engine exhaust, PAHs Polycyclic aromatic hydrocarbons

of global attributable DALYs. The DALYs attributable to occupational injuries, PGFs, ergonomic factors, noise, carcinogens, and asthmagens accounted for 32.4, 28.3, $14.3,12.4,11.7$, and $0.8 \%$ of DALYs attributable to total occupational risks in 2017, respectively. From 1990 to 2017, occupational injuries were consistently the leading risk of attributable DALYs in China. Although agestandardized DALY rate attributable to total occupational risks declined by $56.1 \%$, occupational exposure to trichloroethylene, asbestos, chromium, polycyclic aromatic hydrocarbons (PAHs), and diesel engine exhaust (DEE) increased by more than $20 \%$. Among all related causes, COPD was the leading cause of the attributable burden in 2017 (Table S7).

For different genders, we have not observed a wide difference in SEV between males and females (Table S8). Deaths attributable to total occupational risks in males were over 2.0 times than in females in 2017. As shown in Fig. 1, the leading risk was occupational PGFs for deaths in both sexes, but for DALYs, the leading risk was occupational PGFs in females and occupational injuries in males. DALYs attributable to total occupational risks were higher in males than in females.

Age-standardized death rates attributable to total occupational risks, carcinogens, asthmagens, PGFs, and injuries in the provinces of China grouped by SDI in 2017 are shown in Fig. 2. Compared with high SDI provinces, low SDI provinces had higher death rates attributable to total occupational risks, occupational PGFs, and occupational injuries. Western China, especially for Yunnan and Tibet, had the highest death rates attributable to total occupational risks, while Liaoning and Heilongjiang in Eastern China had the highest death rates attributable to occupational carcinogens. The highest death rates attributable to occupational PGFs and injuries mainly concentrated in Western China. Age-standardized DALY rates attributable to total occupational risks by the provinces of China in 2017 showed similar results that Western China had higher occupational age-standardized DALY rates than other regions in China (Fig. 3).

\section{Discussion}

To our knowledge, this study presents the first comprehensive assessment so far of burden attributable to occupational risks at the provincial level of China in 2017. China has a huge labor force. The most up-todate estimation of the disease burden attributable to occupational exposures provides important insights into health losses related to occupational risks in China. Meanwhile, the standardized assessment of attributable burden to different risk factors enables direct comparison and priority ranking. 
Table 4 DALYs and age-standardized DALY rate for occupational risk factors, 1990, and 2017 in China, with mean percentage change for 1990-2017

\begin{tabular}{|c|c|c|c|c|c|c|}
\hline \multirow[t]{2}{*}{ Occupational risks } & \multicolumn{3}{|l|}{ DALYs, in thousand } & \multicolumn{3}{|c|}{ Age-standardized DALY rate (per 100,000) } \\
\hline & 1990 & 2017 & $\begin{array}{l}\text { Percentage } \\
\text { change (\%) }\end{array}$ & 1990 & 2017 & $\begin{array}{l}\text { Percentage } \\
\text { change (\%) }\end{array}$ \\
\hline Asthmagens & $194.5(144.5-244.7)$ & $114.8(79.8-158.3)$ & $-41.0(-54.5--20.9)$ & $17.39(12.85-21.92)$ & $6.28(4.34-8.68)$ & $-63.9(-72.6--50.8)$ \\
\hline Carcinogens & 766.0(590.4-959.8) & 1650.5(1260.4-2089.6) & 115.5(87.2-147.1) & $78.63(60.59-98.03)$ & $80.49(62.23-101.39)$ & $2.4(-11.2-17.94)$ \\
\hline Arsenic & $40.4(15.7-66.8)$ & 101.8(38.3-167.1) & $152.2(123.1-185.8)$ & 4.05(1.58-6.69) & $4.77(1.80-7.83)$ & $17.9(4.4-33.7)$ \\
\hline Asbestos & 124.8(85.7-190.1) & $442.1(304.7-589.5)$ & $254.3(135.1-375.6)$ & $14.57(10.06-22.02)$ & $22.94(15.85-30.54)$ & 57.5(6.0-108.6) \\
\hline Benzene & $20.1(5.6-33.9)$ & $17.1(5.0-28.7)$ & $-14.7(-27.7-8.8)$ & $1.56(0.44-2.65)$ & 1.01(0.29-1.69) & $-35.5(-45.8--17.8)$ \\
\hline Beryllium & $1.8(1.5-2.1)$ & $4.1(3.3-4.9)$ & $133.7(107.5-160.1)$ & $0.18(0.15-0.21)$ & $0.19(0.16-0.23)$ & $9.3(-2.3-20.5)$ \\
\hline Cadmium & $3.9(3.3-4.6)$ & $10.0(8.3-11.9)$ & $152.9(121.3-187.0)$ & $0.39(0.33-0.46)$ & $0.47(0.39-0.56)$ & $18.2(4.4-34.0)$ \\
\hline Chromium & $7.5(6.6-8.4)$ & $19.9(17.2-22.8)$ & $166.8(135.6-201.4)$ & $0.75(0.66-0.84)$ & $0.93(0.81-1.07)$ & 24.8(10.4-40.6) \\
\hline DEE & $84.3(74.2-95.5)$ & $220.9(190.9-253.5)$ & $161.9(129.2-191.1)$ & $8.45(7.44-9.55)$ & $10.35(8.97-11.87)$ & $22.5(7.5-35.9)$ \\
\hline Formaldehyde & $19.9(15.2-24.8)$ & $16.5(13.0-20.7)$ & $-17.2(-31.4-0.3)$ & $1.64(1.26-2.03)$ & $0.91(0.72-1.12)$ & $-44.6(-52.9--35.0)$ \\
\hline Nickel & $45.5(8.9-101.5)$ & 104.0(20.8-231.5) & $128.7(102.0-158.4)$ & $4.56(0.90-10.19)$ & $4.87(0.98-10.84)$ & $7.0(-5.4-20.8)$ \\
\hline PAHs & $26.0(22.0-29.8)$ & $68.4(57.1-80.0)$ & $163.1(129.3-198.0)$ & $2.60(2.21-2.99)$ & $3.21(2.68-3.76)$ & $23.1(7.9-39.1)$ \\
\hline Silica & $396.2(259.5-548.7)$ & 673.4(395.7-961.1) & $70.0(37.3-99.9)$ & $40.31(26.54-55.58)$ & $32.12(19.09-45.62)$ & $-20.3(-35.6--6.1)$ \\
\hline Sulfuric acid & $13.0(5.4-24.3)$ & $20.9(8.8-39.0)$ & $60.3(45.9-78.7)$ & $1.30(0.54-2.43)$ & $0.97(0.41-1.82)$ & $-25.4(-32.2-16.9)$ \\
\hline Trichloroethylene & $0.1(0.0-0.2)$ & $0.4(0.1-0.8)$ & $244.5(145.3-313.0)$ & $0.01(0.00-0.02)$ & $0.02(0.00-0.04)$ & 66.8(18.3-99.6) \\
\hline Ergonomic factors & 2245.6(1544.9-3125.8) & $2010.5(1372.6-2791.7)$ & $-10.5(-20.4--0.5)$ & $196.81(135.56-275.34)$ & $107.48(74.45-147.55)$ & $-45.4(-50.4--39.5)$ \\
\hline Injuries & $8670.1(7298.9-10,281.7)$ & 4557.6(3748.9-5420.7) & $-47.4(-57.8--34.4)$ & 705.89(594.31-836.67) & 268.58(221.03-319.58) & $-62.0(-69.4--52.5)$ \\
\hline Noise & $1000.0(678.0-1427.0)$ & $1742.2(1186.1-2455.4)$ & $74.2(69.6-79.4)$ & $95.44(65.10-134.64)$ & $90.92(61.88-128.17)$ & $-4.7(-7.0--2.4)$ \\
\hline PGFs & $5281.4(4504.0-6043.7)$ & $3984.6(3368.8-4617.9)$ & $-24.6(-30.6-12.9)$ & $660.90(557.37-760.57)$ & $216.42(181.99-253.00)$ & $-67.2(-69.6--62.2)$ \\
\hline $\begin{array}{l}\text { All occupational } \\
\text { risks }\end{array}$ & $18,157.6(15,945.0-20,433.3)$ & $14,060.2(12,023.0-16,125.8)$ & $-22.57(-30.3-14.0)$ & $1755.07(1543.63-1971.82)$ & $770.18(662.71-885.84)$ & $-56.1(-60.4--51.3)$ \\
\hline
\end{tabular}

UIs Uncertainty intervals, DALYs Disability-adjusted life year, PGFs Particulate matter, gases, and fumes, DEE Diesel engine exhaust, PAHs Polycyclic aromatic hydrocarbons

The SEV provides a concise and comparable summary of risk exposure for different locations and years [15]. Rapid industrialization in China has been accompanied by increased occupational carcinogen exposures. Our study showed SEVs of most occupational carcinogens increased in the past 28 years, especially for asbestos, trichloroethylene. Over the past half-century, the production of asbestos in the world has been transferred to developing countries [21]. China produces about $16 \%$ of global total output and is the second-biggest consumer of asbestos in 2016 [22]. Trichloroethylene use has been increased with China's growing telecommunications, electronic, and microelectronics industries since the early 1990s [23].

China has the largest occupational disease burden in the world. We estimated that 0.3 million deaths and 14.1 million DALYs were attributable to total occupational risks in 2017, China, which might be attributed to the huge number of labor force. Occupational injuries were the leading risk for attributable DALYs in China. A previous report showed occupational injuries and disabilities were common among Chinese workers [24]. In comparison, the leading risk for occupational burden was ergonomic factors in developed countries. Socioeconomic inequality is one of the main reasons for this difference [24-28]. The type and income of occupations, age, and education levels are important influence factors of occupational injuries $[25,26]$. The economic transition from agriculture to manufacturing industry causes the migration of great rural labor forces into factories, and migrant workers have become an important part of the population who are subject to occupational hazards $[29,30]$. For example, migrant workers account for $80 \%$ of total workers in the construction industry [24]. With poor educational backgrounds, migrant workers are only able to locate jobs with low wages, high-risk operation, and long working hours. They also have a lower sense of self-protection and less experience. Almost all of the occupational injuries and deaths are preventable [31]. Therefore, more vocational training and safety education targeting migrant workers are necessary to prevent health loss in China.

Although the burden attributable to all occupational risks is higher in China, it has declined more than 50\% over the past three decades. The Chinese government has made numerous efforts to protect the health of workers in China, including revision of the occupational law, development of new technologies and monitoring of occupational diseases. It is further supported by coincidence 

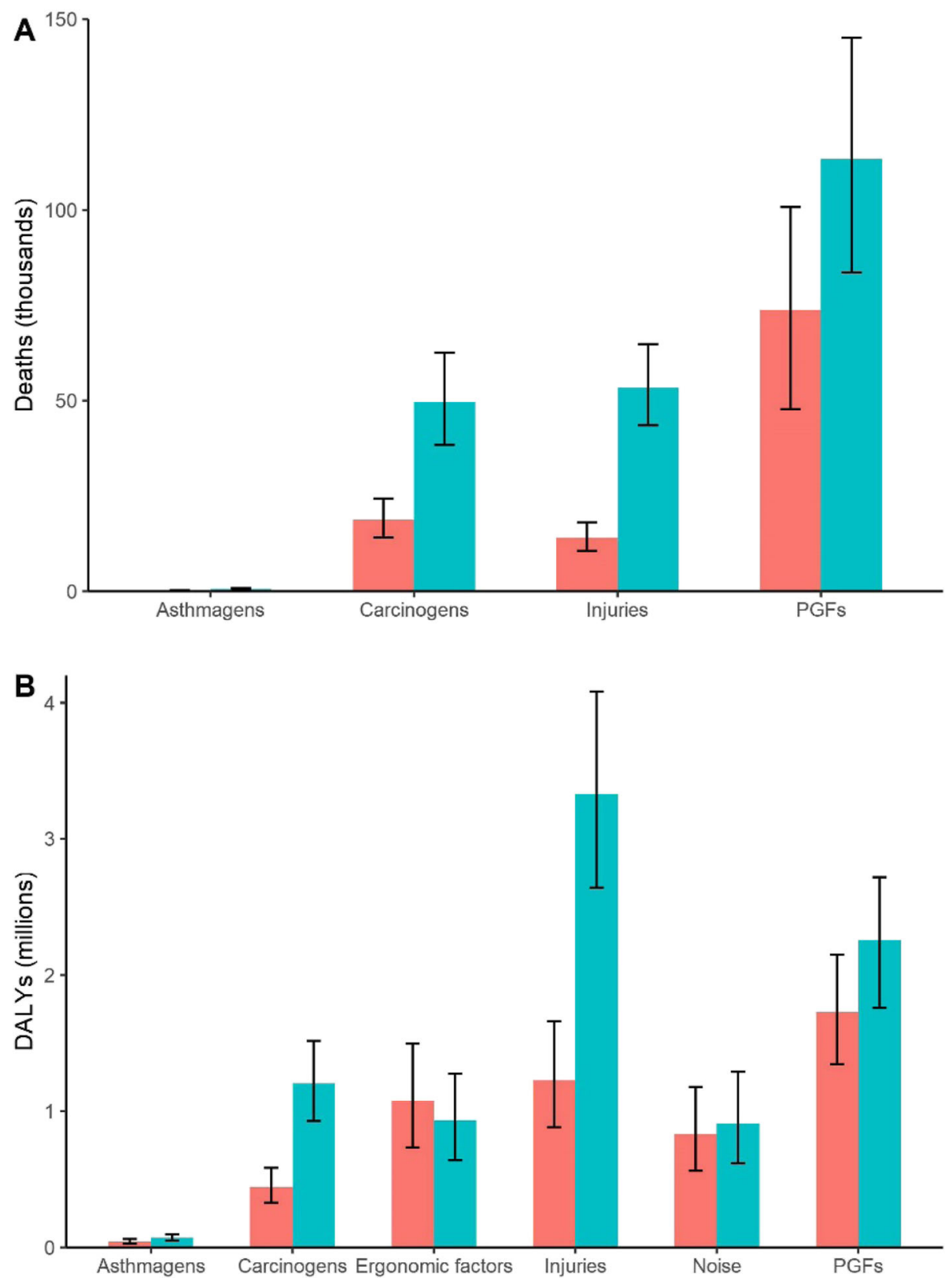

Fig. 1 Burden attributable to occupational risks stratified by gender in China, 2017, for deaths (a), and DALYs (b). DALYs: disability-adjusted life years

of increased SEVs for occupational noises, PGFs, benzene and formaldehyde and reduced burden attributable to these risks. However, the burden attributable to occupational carcinogens, especially for asbestos, trichloroethylene, chromium, PAHs, and DEE still shows marked increases. Notably, among the 13 occupational carcinogens included in this study, only cancers caused by arsenic, asbestos, benzene, and chromium are classified into occupational cancer in the Categories and Catalogs of Occupational Diseases in China. Thus, our results provided basis for policymakers to reevaluate the potential of cancers caused by other nine carcinogens as national legal occupational disease.

The western provinces in China have the highest death and DALY rates attributable to occupational risks. The spatial inequality of disease burden for occupational hazards is similar to previous studies on environmental and occupational burden of diseases in Iran [28, 32], which 


\begin{tabular}{|c|c|c|c|c|c|}
\hline & Occupational risks & Occupational carcinogens & Occupational asthmagens & Occupational PGFs & Occupational injuries \\
\hline China & $18.74(16.17-21.56)$ & $3.50(2.75-4.35)$ & $0.04(0.03-0.05)$ & $11.36(8.82-14.03)$ & $3.84(3.25-4.52)$ \\
\hline \multicolumn{6}{|l|}{ High SDI provinces } \\
\hline Beijing & $9.73(7.69-12.01)$ & $3.36(2.31-4.54)$ & $0.03(0.02-0.05)$ & $4.20(3.02-5.68)$ & $2.13(1.68-2.66)$ \\
\hline Macao & $10.38(8.34-12.73)$ & $2.00(1.48-2.74)$ & $0.02(0.02-0.04)$ & $6.53(4.51-8.54)$ & $1.82(1.35-2.42)$ \\
\hline Hong Kong & $9.12(7.27-12.14)$ & $3.04(2.23-4.06)$ & $0.03(0.02-0.04)$ & $3.36(2.30-5.82)$ & $2.69(2.06-3.47)$ \\
\hline Shanghai & $10.79(8.67-13.47)$ & $2.49(1.71-3.42)$ & $0.02(0.02-0.03)$ & $5.79(4.05-7.98)$ & $2.48(1.95-3.15)$ \\
\hline Tianjin & $12.32(9.81-15.45)$ & $4.41(3.04-6.02)$ & $0.06(0.04-0.08)$ & $5.11(3.72-7.79)$ & $2.74(2.11-3.49)$ \\
\hline Guangdong & $16.12(13.18-19.41)$ & $3.34(2.35-4.58)$ & $0.05(0.03-0.07)$ & $9.61(7.16-12.11)$ & $3.12(2.44-3.91)$ \\
\hline Jiangsu & $17.92(14.43-21.97)$ & $3.20(2.19-4.45)$ & $0.04(0.03-0.05)$ & $11.40(8.37-14.89)$ & $3.28(2.57-4.15)$ \\
\hline Liaoning & $14.20(11.41-18.06)$ & $5.82(4.13-7.78)$ & $0.02(0.02-0.03)$ & $5.14(3.61-9.10)$ & $3.22(2.52-4.07)$ \\
\hline Shandong & $16.21(13.22-19.85)$ & $3.74(2.63-5.00)$ & $0.03(0.02-0.05)$ & $9.17(6.77-12.35)$ & $3.27(2.57-4.15)$ \\
\hline Zhejiang & $15.52(12.44-19.07)$ & $3.35(2.24-4.68)$ & $0.02(0.01-0.03)$ & $8.83(6.38-11.69)$ & $3.32(2.58-4.16)$ \\
\hline \multicolumn{6}{|c|}{ Middle SDI provinces } \\
\hline Fujian & $15.02(12.30-18.10)$ & $3.05(2.09-4.26)$ & $0.07(0.05-0.11)$ & $8.19(5.91-10.73)$ & $3.70(2.91-4.70)$ \\
\hline Inner Mongolia & $17.79(14.49-21.83)$ & $3.75(2.65-5.17)$ & $0.02(0.01-0.02)$ & $10.44(7.72-13.84)$ & $3.58(2.80-4.55)$ \\
\hline Jilin & $11.95(9.60-15.51)$ & $4.46(3.11-6.03)$ & $0.01(0.01-0.02)$ & $3.93(2.71-7.42)$ & $3.54(2.79-4.52)$ \\
\hline Hebei & $17.47(14.39-21.38)$ & $4.53(3.26-6.07)$ & $0.03(0.02-0.04)$ & $9.14(6.70-12.71)$ & $3.77(2.94-4.75)$ \\
\hline Heilongjiang & $16.64(13.33-21.34)$ & $5.51(3.96-7.38)$ & $0.01(0.01-0.01)$ & $7.44(5.30-12.42)$ & $3.68(2.90-4.60)$ \\
\hline Shanxi & $14.05(11.26-17.54)$ & $2.85(1.95-4.01)$ & $0.02(0.02-0.03)$ & $7.37(5.25-10.30)$ & $3.82(2.98-4.81)$ \\
\hline Hubei & $20.45(16.45-24.73)$ & $3.04(2.15-4.15)$ & $0.08(0.05-0.11)$ & $13.44(10.01-17.17)$ & $3.89(3.05-4.93)$ \\
\hline Guangxi & $19.55(15.78-24.28)$ & $2.82(1.94-3.91)$ & $0.07(0.05-0.11)$ & $12.56(9.15-16.30)$ & $4.09(3.22-5.19)$ \\
\hline Hainan & $14.64(11.64-17.83)$ & $1.43(0.96-2.07)$ & $0.05(0.03-0.07)$ & $9.05(6.34-11.66)$ & $4.12(3.21-5.35)$ \\
\hline Henan & $15.82(12.79-20.29)$ & $2.96(2.15-3.99)$ & $0.02(0.01-0.03)$ & $8.85(6.39-13.22)$ & $3.99(3.16-5.07)$ \\
\hline Hunan & $26.11(21.23-31.81)$ & $5.11(3.68-6.89)$ & $0.04(0.02-0.05)$ & $16.93(12.58-21.64)$ & $4.04(3.19-5.18)$ \\
\hline Shaanxi & $13.42(10.98-16.56)$ & $2.36(1.60-3.33)$ & $0.02(0.02-0.03)$ & $6.97(5.18-9.44)$ & $4.07(3.18-5.11)$ \\
\hline Xinjiang & $27.30(21.33-33.65)$ & $2.36(1.79-3.10)$ & $0.05(0.03-0.07)$ & $20.89(15.09-27.04)$ & $3.99(3.12-5.05)$ \\
\hline \multicolumn{6}{|l|}{ Low SDI provinces } \\
\hline Chongqing & $23.85(19.23-29.71)$ & $3.27(2.28-4.68)$ & $0.03(0.02-0.05)$ & $16.22(12.06-21.06)$ & $4.33(3.41-5.47)$ \\
\hline Sichuan & $28.46(22.94-34.74)$ & $3.53(2.49-4.74)$ & $0.03(0.02-0.04)$ & $20.53(15.41-26.08)$ & $4.37(3.42-5.50)$ \\
\hline Jiangxi & $23.08(18.71-27.87)$ & $3.77(2.82-5.01)$ & $0.04(0.03-0.06)$ & $14.57(10.88-18.54)$ & $4.70(3.71-5.84)$ \\
\hline Ningxia & $16.32(13.23-19.77)$ & $1.77(1.24-2.47)$ & $0.03(0.02-0.05)$ & $9.77(7.18-12.67)$ & $4.75(3.69-6.01)$ \\
\hline Anhui & $16.74(13.66-20.43)$ & $2.71(1.88-3.71)$ & $0.04(0.03-0.06)$ & $9.13(6.62-12.21)$ & $4.86(3.82-6.05)$ \\
\hline Qinghai & $27.23(21.86-32.90)$ & $2.48(1.82-3.24)$ & $0.03(0.02-0.04)$ & $19.68(14.91-24.96)$ & $5.05(3.91-6.43)$ \\
\hline Yunnan & $30.11(24.21-36.73)$ & $2.95(2.19-4.00)$ & $0.10(0.06-0.14)$ & $21.95(16.55-28.54)$ & $5.10(4.03-6.35)$ \\
\hline Gansu & $27.18(21.76-32.99)$ & $2.25(1.66-3.03)$ & $0.03(0.02-0.04)$ & $19.58(14.57-24.98)$ & $5.32(4.17-6.77)$ \\
\hline Guizhou & $26.64(21.88-31.66)$ & $2.98(2.05-4.01)$ & $0.11(0.07-0.16)$ & $17.63(13.43-22.14)$ & $5.93(4.56-7.56)$ \\
\hline Tibet & $32.12(26.00-39.49)$ & $1.23(0.90-1.69)$ & $0.07(0.04-0.10)$ & $22.06(16.66-28.57)$ & $8.77(6.93-11.23)$ \\
\hline
\end{tabular}

Ratio of provincial age-standardized death rates(per 100,000 ) to the median death rate of all provinces

$\square<0.75 \square 0.75-0.99 \square 1.00-1.24 \square 1.25-1.49 \square 1.50-1.74 \square>=1.75$

Fig. 2 Age-standardized death rates (per 100,000) attributable to total occupational risks, occupational carcinogens, occupational asthmagens, occupational PGFs, and occupational injuries in the provinces of China grouped by SDI, 2017. SDI: socio-demographic index; PGFs: particulate matter, gases, and fumes 


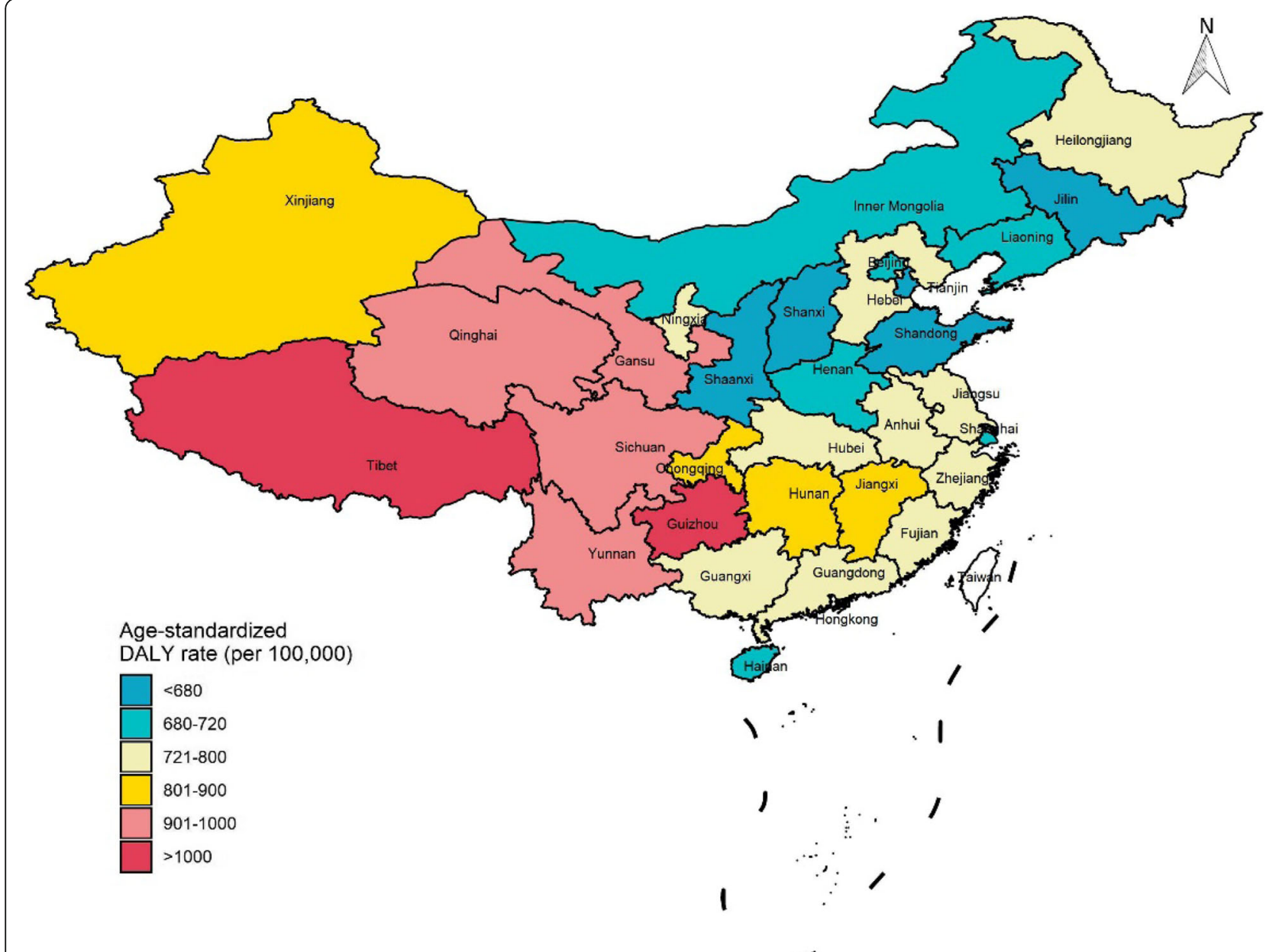

Fig. 3 Age-standardized DALY rate (per 100,000) attributable to total occupational risks by the provinces of China, 2017. DALY: disability-adjusted life-year

might be attributed to the regional inequality of socioeconomic level and medical services of occupational diseases. Institutions certificated to diagnose the occupational disease concentrate in big cities and developed areas, with few institutions in less developed areas, especially for Western China. The imbalance between supply and demand is challenging the medical services of occupational diseases for workers from the western region.

A number of limitations exist in our estimates. The most important limitation is the lack of accessible data on the prevalence of occupational exposure in China. Scarce data are available for the specific exposure levels of occupational risks, compared with air pollution and hazards in drinking water [11, 33-35]. The exposure levels are estimated by the proportion of the population in specific types of work where the exposures are expected. The exposure assessment for occupational carcinogens was based on carcinogen exposure (CAREX) database, which included 32 million workers exposed to almost all known and suspected carcinogens in the 15 countries of the European
Union in the early 1990s [36, 37]. However, workers in developing countries are likely to be exposed to higher levels of occupational hazards than developed countries. Employing CAREX data may underestimate the health effects in developing countries [38]. Meanwhile, China is a top producer of cement, coal, iron, steel with rich mineral reserves and resources. Rapid industrialization in China in recent years also brings more categories of jobs and occupational hazards. More efforts are required to more accurately determine the proportion of the working population exposed to occupational hazards in China.

Due to the stringent causal criteria, many risk-outcome pairs were hampered to be included in GBD estimates, which leads to underestimation of the disease burden attributable to occupational risks, in comparison with other published studies [39-42]. For example, benzene can cause not only leukemia but also myelodysplastic syndromes, multiple myeloma and non-Hodgkin lymphoma [43-45]. Apart from lung cancer, arsenic exposure can also cause urothelial cancer, skin cancer, and 
cardiovascular diseases [46]. Meanwhile, disabilities in GBD methods are associated with health conditions confined to the most common sequelae of occupational exposure but not mental disorders [42, 47]. Furthermore, there are joint effects attributable to co-exposure of multiple occupational hazards. For example, exposure to benzene interacts with work stress can reduce birth weight in petrochemical workers [48]. As most of the occupational risk-outcome pairs cannot be accessed by randomized controlled trials, evidence from epidemiological studies and toxicological studies deserves consideration in future estimates [49].

Finally, there are many uncertainties of applying the default parameters from the developed country to China. The relative risk is a critical parameter for the PAF and SEV estimations. It is derived from prospective observational studies and case-control studies by systematic reviews [15]. However, most of the relative risks come from studies conducted in high-income countries with lower occupational exposure, rather than low- and middle-income countries, which may cause biased estimates of PAF and SEV for a given population [49]. Moreover, the estimation of the TMREL is also a key step in the calculation of the PAF. A minor change of the TMREL can lead to relatively large changes in the PAF [49]. For all occupational risks, the TMREL is defined as no corresponding occupational exposure or background level to a given risk [15]. However, the background level of occupational hazards including carcinogens, asthmagens, and noises is often difficult to specify [36]. Additional epidemiological studies in regions with both high and low occupational exposure should be encouraged and supported to estimate relative risks and TMREL more accurately in China.

A human capital approach is suggested as an alternative method to provide accurate estimates of the impact of chemical exposure on population health $[42,49,50]$. It is a health economic method to assign monetary costs associated with adverse outcomes, including but not limited to traditional physical health such as cognitive deficits [42, 49]. A hybrid approach of the existing GBD method and the human capital approach should be encouraged to obtain more comprehensive and accurate estimates of the burden attributable to occupational risks.

Although the current method in GBD could not fully estimate the impacts of occupational risks on population health, the results were estimated from all accessible resources to produce relatively valid estimates up till now. Moreover, we take socioeconomic impact into our estimates to analyze differences among regions with different levels of development. Further work to increase the quality and availability of data are expected to devote adequate evidence for more valid estimates in China.
In conclusion, China is facing a tremendous disease burden attributable to occupational risk factors. Although the burden attributable to total occupational risks decreased between 1990 and 2017, the burden attributable to occupational carcinogens is rising greatly. The attributable burden is higher in males, and in less developed provinces of Western China. Our estimates will benefit policymakers to focus on preventing and reducing the health losses of workers in China.

\section{Supplementary information}

Supplementary information accompanies this paper at https://doi.org/10. 1186/s12940-020-00577-y.

Additional file 1: Table S1. Occupational risk factors hierarchy, exposure definitions, and TMREL. Table S2. List of ICD codes. Table S3 Epidemiological evidences. Table S4. Relative risks A. Table S5. Relative risks B. Table S6. PAF.

Additional file 2: Table S7. Attributable burden of all occupational risks by causes. Table S8. Sex-specific age-standardized SEVs of occupational risks.

\section{Abbreviations \\ CAREX: Carcinogen exposure database: COPD: Chronic Obstructive Pulmonary Disease; CRA: Comparative risk assessment; DALYs: Disability- adjusted life years; DEE: Diesel engine exhaust; GBD: Global burden of disease; ICD: International Classification of Disease; PAF: Population attributable fraction; PAHs: Polycyclic aromatic hydrocarbons; PGFs: Occupational particulate matter, gases, and fumes; SDI: Socio- demographic index; SEV: Summary exposure value; ST-GPR: Spatio-temporal Gaussian process regression; TMREL: Theoretical minimum risk exposure level; UI: Uncertain interval; YLDs: Years lived with disability; YLLs: Years of life lost}

\section{Acknowledgments}

We acknowledge the contributions of the staff of the Institute for Health Metrics and Evaluation, University of Washington.

\section{Authors' contributions}

$J$, PY, and MZ conceived the study and provided overall guidance. $J \mathrm{~L}$ prepared the first draft and finalized the manuscript based on comments from all other authors. JL, HW, PY, MZ, had major roles in formulating the analysis for China using the Global Burden of Diseases, Injuries, and Risk Factors Study 2017 methods. All other authors contributed to the analysis and reviewed the manuscript. The authors read and approved the final manuscript.

\section{Funding}

This work was supported by the China National Key Research and Development Program (2018YFC1315300) and the Bill \& Melinda Gates Foundation (OPP1152504)

Availability of data and materials

Please contact the author for data requests.

Ethics approval and consent to participate Not applicable.

Consent for publication

All of the authors have reviewed and approved the manuscript for publication.

Competing interests

The authors declare that they have no competing interests. 


\section{Author details}

National Center for Chronic and Noncommunicable Disease Control and Prevention, Chinese Center for Disease Control and Prevention, 27 Nanwei Road, Xicheng District, Beijing 100050, China. ${ }^{2}$ Institute for Health Metrics and Evaluation, University of Washington, Seattle, WA, USA. ${ }^{3}$ Chinese Center for Disease Control and Prevention, Beijing, China.

\section{Received: 12 November 2019 Accepted: 11 February 2020}

\section{- 20.0}

\section{References}

1. National Bureau of Statistics. China Statistical Yearbook 2016. http://www. stats.gov.cn/tjsj/ndsj/2016/indexch.htm. Accessed 20 Oct 2019.

2. National Health Commission of People's Republic of China. 2019. http:// www.nhc.gov.cn/wjw/spxw/201907/f9d54e4a8e054e14bd2a385194fc0334. shtml. Accessed 20 Oct 2019.

3. Blanc PD, Iribarren C, Trupin L, Earnest G, Katz PP, Balmes J, et al. Occupational exposures and the risk of COPD: dusty trades revisited. Thorax. 2009;64(1):6-12.

4. Toren $\mathrm{K}$, Jarvholm B. Effect of occupational exposure to vapors, gases, dusts, and fumes on COPD mortality risk among Swedish construction workers: a longitudinal cohort study. Chest. 2014;145(5):992-7.

5. Boffetta P, Fryzek JP, Mandel JS. Occupational exposure to beryllium and cancer risk: a review of the epidemiologic evidence. Crit Rev Toxicol. 2012; 42(2):107-18.

6. Lenters $V$, Vermeulen $R$, Dogger $S$, Stayner L, Portengen L, Burdorf A, et al, A meta-analysis of asbestos and lung cancer: is better quality exposure assessment associated with steeper slopes of the exposure-response relationships? Environ Health Perspect. 2011;119(11):1547-55.

7. Armstrong B, Hutchinson E, Unwin J, Fletcher T. Lung cancer risk after exposure to polycyclic aromatic hydrocarbons: a review and meta-analysis. Environ Health Perspect. 2004;112(9):970-8.

8. Liu Y, Steenland K, Rong Y, Hnizdo E, Huang $X$, Zhang H, et al. Exposureresponse analysis and risk assessment for lung cancer in relationship to silica exposure: a 44-year cohort study of 34,018 workers. Am J Epidemiol. 2013;178(9):1424-33

9. Pruss-Ustun A, Wolf J, Corvalan C, Neville T, Bos R, Neira M. Diseases due to unhealthy environments: an updated estimate of the global burden of disease attributable to environmental determinants of health. J Public Health (Oxf). 2017;39(3):464-75.

10. Guan WJ, Zheng XY, Chung KF, Zhong NS. Impact of air pollution on the burden of chronic respiratory diseases in China: time for urgent action. Lancet. 2016:388(10054):1939-51.

11. Cohen AJ, Brauer M, Burnett R, Anderson HR, Frostad J, Estep K, et al. Estimates and 25-year trends of the global burden of disease attributable to ambient air pollution: an analysis of data from the global burden of diseases study 2015. Lancet. 2017;389(10082):1907-18.

12. Li P, Deng SS, Wang JB, Iwata A, Qiao YL, Dai XB, et al. Occupational and environmental cancer incidence and mortality in China. Occup Med (Lond). 2012:62(4):281-7.

13. Tse LA, Yu IT, Qiu H, Au JS, Wang XR. Occupational risks and lung cancer burden for Chinese men: a population-based case-referent study. Cancer Causes Control. 2012;23(1):121-31.

14. Ma R, Zhong S, Morabito M, Hajat $S, X u Z$, He Y, et al. Estimation of workrelated injury and economic burden attributable to heat stress in Guangzhou, China. Sci Total Environ. 2019:666:147-54.

15. GBD 2017 Risk Factor Collaborators. Global, regional, and national comparative risk assessment of 84 behavioural, environmental and occupational, and metabolic risks or clusters of risks for 195 countries and territories, 1990-2017: a systematic analysis for the global burden of disease study 2017. Lancet. 2018;392(10159):1923-94.

16. GBD 2017 Causes of Death Collaborators. Global, regional, and national agesex-specific mortality for 282 causes of death in 195 countries and territories, 1980-2017: a systematic analysis for the global burden of disease study 2017. Lancet. 2018:392(10159):1736-88.

17. GBD 2016 Risk Factors Collaborators. Global, regional, and national comparative risk assessment of 84 behavioural, environmental and occupational, and metabolic risks or clusters of risks, 1990-2016: a systematic analysis for the global burden of disease study 2016. Lancet. 2017;390(10100):1345-422.
18. GBD 2017 Disease and Injury Incidence and Prevalence Collaborators. Global, regional, and national incidence, prevalence, and years lived with disability for 354 diseases and injuries for 195 countries and territories, 1990-2017: a systematic analysis for the global burden of disease study 2017. Lancet. 2018;392(10159):1789-858.

19. Zhou M, Wang H, Zeng $X$, Yin $P$, Zhu J, Chen W, et al. Mortality, morbidity, and risk factors in China and its provinces, 1990-2017: a systematic analysis for the global burden of disease study 2017. Lancet. 2019;394(10204):1145-58.

20. Rockhill B, Newman B, Weinberg C. Use and misuse of population attributable fractions. Am J Public Health. 1998;88(1):15-9.

21. Le GV, Takahashi K, Park EK, Delgermaa V, Oak C, Qureshi AM, et al. Asbestos use and asbestos-related diseases in Asia: past, present and future. Respirology. 2011;16(5):767-75.

22. United States Geological Survey. Minerals yearbook: asbestos, 2016. https:// s3-us-west-2.amazonaws.com/prd-wret/assets/palladium/production/ mineral-pubs/asbestos/mcs-2016-asbes.pdf. Accessed 20 Oct 2019.

23. Friesen MC, Locke SJ, Chen YC, Coble JB, Stewart PA, Ji BT, et al. Historical occupational trichloroethylene air concentrations based on inspection measurements from Shanghai, China. Ann Occup Hyg. 2015; 59(1):62-78

24. Wang $\mathrm{H}$, Chen $\mathrm{G}$, Wang Z, Zheng $X$. Socioeconomic inequalities and occupational injury disability in China: a population-based survey. Int J Environ Res Public Health. 2015;12(6):6006-15.

25. Aragon A, Partanen T, Felknor S, Corriols M. Social determinants of workers' health in Central America. Int J Occup Environ Health. 2011;17(3):230-7.

26. Burrows S, Auger N, Gamache P, Hamel D. Individual and area socioeconomic inequalities in cause-specific unintentional injury mortality: 11-year follow-up study of 2.7 million Canadians. Accid Anal Prev. 2012;45: 99-106.

27. Steenland K, Halperin W, Hu S, Walker JT. Deaths due to injuries among employed adults: the effects of socioeconomic class. Epidemiology. 2003; 14(1):74-9.

28. Abtahi M, Koolivand A, Dobaradaran S, Yaghmaeian K, Mohseni-Bandpei A, Khaloo SS, et al. National and sub-national age-sex specific and causespecific mortality and disability-adjusted life years (DALYS) attributable to household air pollution from solid cookfuel use (HAP) in Iran, 1990-2013. Environ Res. 2017;156:87-96.

29. Gong P, Liang S, Carlton EJ, Jiang Q, Wu J, Wang L, et al. Urbanisation and health in China. Lancet. 2012;379(9818):843-52.

30. Zhang X, Wang Z, Li T. The current status of occupational health in China. Environ Health Prev Med. 2010;15(5):263-70.

31. Ringen K, Seegal J, Englund A. Safety and health in the construction industry. Annu Rev Public Health. 1995;16:165-88.

32. Abtahi M, Koolivand A, Dobaradaran S, Yaghmaeian K, Khaloo SS, Jorfi S, et al. National and subnational mortality and disability-adjusted life years (DALYs) attributable to 17 occupational risk factors in Iran, 1990-2015. Environ Res. 2018:165:158-75.

33. Abtahi M, Dobaradaran S, Jorfi S, Koolivand A, Khaloo SS, Spitz J, et al. Age-sex specific disability-adjusted life years (DALYS) attributable to elevated levels of fluoride in drinking water: a national and subnational study in Iran, 2017. Water Res. 2019:157:94-105.

34. Dobaradaran S, Shabankareh Fard E, Tekle-Rottering A, Keshtkar M, Karbasdehi VN, Abtahi M, et al. Age-sex specific and cause-specific health risk and burden of disease induced by exposure to trihalomethanes (THMs) and haloacetic acids (HAAs) from drinking water: an assessment in four urban communities of Bushehr Province, Iran, 2017. Environ Res. 2019;182: 109062.

35. Abtahi M, Dobaradaran S, Torabbeigi M, Jorfi S, Gholamnia R, Koolivand $A$, et al. Health risk of phthalates in water environment: occurrence in water resources, bottled water, and tap water, and burden of disease from exposure through drinking water in Tehran, Iran. Environ Res. 2019:173:469-79.

36. Kauppinen T, Toikkanen J, Pedersen D, Young R, Ahrens W, Boffetta P, et al. Occupational exposure to carcinogens in the European Union. Occup Environ Med. 2000;57(1):10-8

37. Kauppinen T, Toikkanen J, Pederson D, Young R, Kogevinas M, Ahrens W, et al. Occupational exposure to carcinogens in the European Union in 1990-93. Helsinki: Finnish Institute of Occupational Health; 1998.

38. Nelson Dl, Concha-Barrientos M, Driscoll T, Steenland K, Fingerhut M, Punnett $L$, et al. The global burden of selected occupational diseases and injury risks: methodology and summary. Am J Ind Med. 2005;48(6):400-18. 
39. Harris EC, Palmer KT, Cox V, Darnton A, Osman J, Coggon D. Trends in mortality from occupational hazards among men in England and Wales during 1979-2010. Occup Environ Med. 2016;73(6):385-93.

40. Rushton L, Hutchings SJ, Fortunato L, Young C, Evans GS, Brown T, et al. Occupational cancer burden in Great Britain. Br J Cancer. 2012;107(Suppl 1): S3-7.

41. Takala J, Hamalainen P, Saarela KL, Yun LY, Manickam K, Jin TW, et al. Global estimates of the burden of injury and illness at work in 2012. J Occup Environ Hyg. 2014;1 1(5):326-37.

42. Grandjean P, Bellanger M. Calculation of the disease burden associated with environmental chemical exposures: application of toxicological information in health economic estimation. Environ Health. 2017;16(1):123.

43. Bassig BA, Friesen MC, Vermeulen R, Shu XO, Purdue MP, Stewart PA, et al. Occupational exposure to benzene and non-Hodgkin lymphoma in a population-based cohort: the Shanghai women's health study. Environ Health Perspect. 2015;123(10):971-7.

44. Schnatter AR, Glass DC, Tang G, Irons RD, Rushton L. Myelodysplastic syndrome and benzene exposure among petroleum workers: an international pooled analysis. J Natl Cancer Inst. 2012;104(22):1724-37.

45. Stenehjem JS, Kjaerheim K, Bratveit M, Samuelsen SO, Barone-Adesi F, Rothman N, et al. Benzene exposure and risk of lymphohaematopoietic cancers in 25000 offshore oil industry workers. Br J Cancer. 2015;112(9): 1603-12.

46. Kuo CC, Moon KA, Wang SL, Silbergeld E, Navas-Acien A. The Association of arsenic metabolism with cancer, cardiovascular disease, and diabetes: a systematic review of the epidemiological evidence. Environ Health Perspect. 2017;125(8):087001.

47. Bellinger DC. Applying methods of the global burden of diseases, injuries, and risk factors study to developmental neurotoxicants: a commentary. Environ Health. 2018;17(1):53.

48. Chen D, Cho SI, Chen C, Wang X, Damokosh Al, Ryan L, et al. Exposure to benzene, occupational stress, and reduced birth weight. Occup Environ Med. 2000;57(10):661-7.

49. Shaffer RM, Sellers SP, Baker MG, de Buen KR, Frostad J, Suter MK, et al. Improving and expanding estimates of the global burden of disease due to environmental health risk factors. Environ Health Perspect. 2019;127(10): 105001.

50. Becker GS. Investment in Human Capital: a theoretical analysis. J Pol Econ. 1962;70(5):9-49.

\section{Publisher's Note}

Springer Nature remains neutral with regard to jurisdictional claims in published maps and institutional affiliations.

Ready to submit your research? Choose BMC and benefit from:

- fast, convenient online submission

- thorough peer review by experienced researchers in your field

- rapid publication on acceptance

- support for research data, including large and complex data types

- gold Open Access which fosters wider collaboration and increased citations

- maximum visibility for your research: over $100 \mathrm{M}$ website views per year

At BMC, research is always in progress.

Learn more biomedcentral.com/submissions 